\title{
Correspondencia entre Rejas. La Defensa de la Libertad por Teresa Mañé Miravent
}

\author{
Ginés Puente Pérez* \\ Universitat Rovira i Virgili, Tarragona, Spain
}

\begin{abstract}
Teresa Mañé Miravent (1865-1939), also known under the pseudonym of Soledad Gustavo, is one of the most important woman regarding the development of the Spanish anarchist school of thought. Her incisive pen, as well as her assiduous participation in anarchist parties and activities, made her an influential theoretician in both national and international working press. In this article, I will analyse the epistolary relations that Teresa Mañé exchanged while searching for the defence of freedom and anarchist ideology in nineteenth-century Spain and the first decades of the twentieth century.
\end{abstract}

Keywords: Anarchism, assistance prisoners, workers' prisons, Teresa Mañé Miravent and Soledad Gustavo.

Resumen. Teresa Mañé Miravent (1865-1939), conocida bajo el pseudónimo de Soledad Gustavo, es una de las mujeres más importantes en la formación del pensamiento anarquista del Estado español. Su pluma incisiva, así como su asidua participación en veladas y actividades anarquistas, hicieron de ella una influyente teórica en la prensa obrera nacional e internacional. En este artículo analizaré las relaciones

\footnotetext{
* Author's address:

Departament d'Història i Història de l'Art

Universitat Rovira i Virgili

Av. Catalunya 35, 43002 Tarragona, Spain

E-mail ginespuenteperez@gmail.com
} 
epistolares que Teresa Mañé mantuvo en la búsqueda de la defensa de la libertad y del ideario anarquista en la España del siglo XIX y primeras décadas del XX.

Palabras clave: Anarquismo, asistencia presos, cárceles obreras, Teresa Mañé Miravent y Soledad Gustavo.

\section{Introito}

El análisis del epistolario internacional anarquista encierra la problemática de la censura de muchas de las cartas enviadas, por la sospecha de las autoridades ante la afiliación política de emisores y/o receptores. Fue por este motivo por el que la mayoría de estas cartas se abrieron -y muchas veces se depuraron- antes de su envío o recepción. El objetivo no fue otro que el control y represión de las mentalidades ácratas y librepensadoras. A pesar de ello, el internacionalismo anarquista funcionó de una manera excelente. La información se trasladó, de una manera eficaz y rápida, de un lugar a otro del mundo. Comprometidos con la causa, no titubearon en coger pluma y papel para plasmar sus inquietudes y quejas. Cartas que reflejan el interés por explorar, conocer y aprender de otras ideas y de otras culturas.

Aunque la historiografía durante años ha menospreciado y ocultado la relevancia que tuvo el anarquismo y el anarco-feminismo en el Estado español, éstos representaron, desde la segunda mitad del siglo XIX hasta la victoria franquista en 1939, una ideología fundamental para la comprensión de la sociedad civil y política. Si se profundiza en este contexto histórico y sociopolítico, nos adentramos en un mundo complejo y, a su vez, convulso. Nos encontramos en un periodo de cambio, de transición; una etapa de consolidación del Capitalismo en detrimento del Antiguo Régimen.

Las realidades políticas que protagonizan el final del siglo XIX y primeras décadas del siglo XX son el resultado de un proceso histórico cuyos relatos, como digo, son a menudo sesgados y/u ocultados. Por eso, conseguir desvelar algunos de estos silencios que existen sobre ese pasado, en este caso la lucha de Teresa Mañé con respecto a los presos obreros, se presenta como una labor necesaria si queremos encaminarnos hacia un futuro en el que la libertad se articule como el eje central del presente. De esta manera, daremos visibilidad a todas aquellas mujeres y colectivos que, por el hecho de ser transgresores y/o estar al margen de lo socialmente establecido como correcto, han sido apartados y borrados de nuestras memorias contemporáneas (Meijome 2013: 81-94; Biglia 2012; England 1994). 


\section{Teresa Mañé Miravent}

El nacimiento de Teresa Mañé Miravent, el 29 de noviembre del 1865 en Cubelles (Garraf, Barcelona), coincide con el surgimiento del anarquismo en el Estado español el 1868; fecha en la que el napolitano Giuseppe Fanelli (18271877), miembro de una organización de seguidores de Mikhaïl Bakunin (18141876), en dos viajes relámpago a Barcelona y Madrid, promulgó la necesidad de crear un colectivo español que representara a la Asociación Internacional de Trabajadores (AIT).

Teresa nació en el seno de una familia republicana un tanto acomodada, lo que le permitió el acceso a la escuela pública de niñas de Vilanova i la Geltrú, donde pasó su infancia y juventud. Sus excelentes calificaciones y su interés por la pedagogía le ayudaron a acceder a la Escuela Normal de Barcelona, donde cursó la carrera de magisterio - que nunca finalizaría-, al mismo tiempo que ejerció como maestra. Ya en esta etapa manifestó su interés y coraje por conocer nuevas formas de pensamiento. Es por eso que recibió, y debe recibir, los calificativos de pionera en cuanto al laicismo pedagógico.

La preocupación por la educación fue una constante en su vida. El contacto que mantuvo con ilustrados como Bartolomé Gabarró Borràs (1845-?) -precursor de las primeras escuelas laicas en el Estado español-, despertó en ella el interés por este tipo de enseñanza, que aplicaría, más tarde, en su escuela de Vilanova i la Geltrú (Micó 2001). Ésta, además de laica, era únicamente para niñas, lo cual daba cabida a aquella parte de la población que no tenía igual acceso a la educación. Su evolución se verá reflejada en la tipología de centro que funda junto con Joan Montseny Carret (1864-1942), años después, en Reus. En la escuela laica, de esta última localidad, las asignaturas de las niñas fueron, dentro de lo posible, muy similares a las de los niños; se preparaba, de este modo, a las mujeres para la sociedad futura, para que participasen en su formación de una manera crítica y decisiva. Este modelo sería el antecesor de La Escuela Moderna promovida por su buen amigo Francesc Ferrer i Guàrdia (1859-1909).

La obra de Soledad Gustavo es extensa y sus contenidos varios; trató cuestiones como la teoría anarquista o la lucha obrera, pero también sobre el amor libre, el matrimonio y el divorcio, la emancipación de la mujer, la religión y la pedagogía (Iturbe 1994; Martín \& Palomar 2010; Prado 2011).

Teresa Mañé tuvo muy claro desde joven que, para materializar su idea de sociedad futura, era necesario instruir y formar a todo el mundo. Bajo este 
significado absoluto, comprendió que debía educarse de igual modo a los hijos del burgués y del obrero, al obrero analfabeto o al privado de libertad. Sin embargo, a pesar del discurso pedagógico de gran parte del movimiento obrero, como reconoce Luis Gargallo en su tesis doctoral (2014: 490), el anarquismo fue criminalizado desde sus primeras manifestaciones. En 1884, el italiano Cesare Lombroso (1835-1909) argumentó que entre las manifestaciones de delito político se encontraba la personalidad anarquista (Girón 2002: 81-108). El autor italiano, que encontró oposición en Ricardo Mella Cea (1861-1925) y Joan Montseny, resumía el problema del anarquismo de la siguiente manera:

$\mathrm{Y}$ he demostrado ya en muchas de mis obras que, mientras todos los hombres experimentan algo de repugnancia hacia todo lo nuevo, los locos, criminales natos y apasionados sienten hacia ello una imperiosa atracción, que, dada su poca cultura y su enfermedad, se manifiesta en inútiles bizarrías y originales crueldades. (Lombroso 1876: 26).

De hecho, esta idea equívoca del ideario anarquista, junto con la lucha en contra del sistema, fue la principal causa de la represión y persecución política y policial.

Piotr A. Kropotkin (1842-1921), de quien Teresa Mañé se había declarado discípula junto con Élisée Reclus (1830-1905)² , había pronunciado un crítico discurso, el 20 de diciembre de 1877 en París, titulado "Las cárceles y su influencia moral sobre los presos". Pronto, la palabra se convertiría en texto y, bien seguro, llegaría a las manos de Teresa, quien fue lectora y traductora del francés. El autor ruso se preguntaba y planteaba al público: "Es hora ya de que nos preguntemos si la condena a muerte o a la cárcel son justas. ¿Logran el doble fin que se marcan como objetivo, el de impedir la repetición del acto antisocial y (en cuanto a las cárceles) el de reformar al infractor?". El interrogante era una cuestión latente en la sociedad del novecientos, como consecuencia de la persecución, por parte de los organismos estatales, a personas, entidades y organismos opuestos a los poderes fácticos. Para Kropotkin, como para la mayoría de ácratas, las prisiones debían desaparecer, ya que su función era banal y moralizante y, además, era imposible mejorar su sistema de instrucción: "Con excepción de unas cuantas mejoras insignificantes, no se puede hacer absolutamente nada más que demolerla".

${ }^{2}$ Mañé, T. (1923). El progreso en nuestras ideas. La Revista Blanca, 01-09-1923. 
De hecho, el debate sobre las estrategias de dominación se había generado mucho tiempo atrás. Por ejemplo, Charles Louis de Secondat, señor de la Brède y barón de Montesquieu (1689-1755), señaló que los castigos aumentaban o disminuían en la medida en que los gobiernos alentaban o desalentaban la libertad. Posteriormente, Alexis Henri Charles de Clérel, vizconde de Tocqueville (1805-1859), en 1833, escribió que la ironía de la libertad propugnada en los Estados Unidos venía unida a la miseria de sus cárceles, propias de regímenes autoritarios ${ }^{3}$. El castigo fue el reflejo de la sociedad en la que se impuso, mostrando la forma de hacer frente a las tensiones y problemas que se dieron en ella (Gargallo 2014: 21).

En el Estado español es necesario reconocer a Concepción Arenal (18201893), considerada una de las madres del feminismo burgués y una de las pocas mujeres que se atrevió a plantar cara al sistema penitenciario. Aunque en ningún caso fue abolicionista de estos espacios de castigo, con obras como Cartas a los delincuentes (1865), Oda a la esclavitud (1866) -premiada por la Sociedad Abolicionista de Madrid-, El reo, el pueblo y el verdugo o La ejecución de la pena de muerte (1867) se demostró su compromiso ante la precaria situación de los presos. En 1863, se convirtió en la primera mujer que recibió el título de Visitadora de Cárceles de Mujeres, cargo que ostentó hasta 1865 .

Las propuestas y consideraciones de Arenal se distanciaban mucho de lo que sostenían y defendían anarquistas como Mañé. Decía Arenal, en una carta pública dirigida a los presos, que:

En la prisión, como en el mundo, suelen tener menos tolerancia los que más la necesitan de los otros para sus faltas, y no parece sino que exigimos las virtudes ajenas por la medida de los vicios propios. Tal inconsecuencia no se ve nunca tan manifiesta como en los que, habiendo atacado la propiedad ajena, son atacados en la propia [...] Dios graba en nuestro corazón más profundamente las verdades que son más importantes; y como el derecho de propiedad es muy necesario, está escrito en nuestra conciencia de tal modo, que nadie pueda borrarle. Lo reclaman con la misma energía el bandolero en su cuadrilla, el obrero en su taller, el confinado en su prisión, y el sabio en su cátedra, porque en todas partes es igualmente preciso, pues sin el respecto a

${ }^{3}$ Montesquieu (1762). El espíritu de las leyes, p. 88; y Beaumont, G. de \& Tocqueville, A. de (1833). On the penitentiary system in the United States, p. 47. 
la propiedad la sociedad sería el caos y poco después nada. (Arenal, Carta a los delincuentes, 1865).

Esta evidente crítica al hurto y hacia las reivindicaciones por parte del comunismo-anárquico de la abolición de la propiedad privada, juntamente con continuas referencias a Dios, fueron fundamentales en su discurso. Para la autora gallega, las cárceles debían reformular sus metodologías y ayudar a los presos a alcanzar el arrepentimiento cristiano:

¿Y en las prisiones podrán ser de alguna utilidad? ¿Los hombres y las mujeres que en ellas se encierran quieren escuchar, pueden comprender lo que les decimos, y caso de que nos escuchen y nos comprendan, podrán o querrán corregirse y enmendarse? Sobre esto hay diferentes opiniones. La nuestra es que los criminales son personas y no son cosas. Que los criminales escuchan al que les habla inspirado por el deseo de su bien. Que los criminales comprenden al que con caridad les explica. Que los criminales, salvo algunas excepciones, no son monstruos fuera de todas las leyes morales, a quienes es imposible aplicar ninguna regla, sino dolientes del alma, en los que, como los del cuerpo, salvo el órgano y órganos, enfermos, los demás funcionan con regularidad y conforme a las leyes establecidas por Dios para todos los seres [...] Creemos que hay algunos criminales que pueden corregirse, y muchos que pueden modificarse, llegando, si no a ser buenos, a no hacer mal [...] Creemos que la primera condición para que el castigo moralice es el convencimiento, por parte del que le sufre, de que es justo; y porque creemos todo esto, hemos escrito estas cartas... (Arenal, Carta a los delincuentes, 1865).

Décadas más tarde, el filósofo francés Michel Foucault (1926-1984) defendía que el castigo disciplinario, es decir, el adoctrinamiento moral que planteaba Arenal y criticaba Kropotkin, actuaba como un mecanismo de poder dentro de estrategias más amplias de dominación, (ver traducción al español en el 2000). De hecho, la desigualdad de clase, tal y como justifica el autor, unida a la mayor influencia de las clases dominantes burguesas en la creación y aplicación de los códigos legales, y por extensión en el control del sistema penitenciario, hacían necesario tener presente la utilización de estos elementos para perpetuar las diferencias y proteger los privilegios. 
A pesar de todo, el miedo generado por las autoridades no ahuyentó a anarquistas como Teresa Mañé en la defensa de sus convicciones y de los que, privados de libertad, pensaron como ella.

\section{El Anarquismo dentro de las Cárceles: Pedagogía y Persecución}

La educación se convirtió en el motor de transformación social defendida por el comunismo libertario. Años más tarde al discurso que había formulado Kropotkin en París, Teresa Mañé preguntaba a sus lectores:

¿Son buenos todos los métodos de instrucción que recibe el pueblo? ¿Responden á la marcha del progreso? Preguntas son éstas, que por sí solas, entrañan un orden de ideas admirables y sublimes si se saben comprender y se interpretan tal como queremos sean interpretadas ${ }^{4}$.

Mañé, en la escuela de Vilanova i la Geltrú primero y, más tarde en la de Reus, junto a Joan Montseny, incorporó un horario vespertino dirigido a aquellos obreros que querían aprender a leer y a escribir. Su idea se fundamentaba, como se ha avanzado en la introducción, en que todo el mundo debía instruirse para conseguir la verdadera revolución social anarquista y establecer, de esta manera, la Sociedad Futura.

La enseñanza, para cumplir su misión, debe abrazar en su seno la idea de la libertad y la tolerancia, del amor á la humanidad entera, sin distinción de razas ni de religiones: todos somos hermanos en naturaleza, todos debemos ser educados e instruidos en la escuela de la fraternidad [...] Y el objetivo primordial de la enseñanza debe ser preparar seres, hacerlos experimentados é instruidos para que después de estudiar la bondad de las acciones de los hombres, la verdad ó mayor certeza de las ideas, sigan una senda con buenos fines y con pleno conocimiento de causa ${ }^{5}$.

\footnotetext{
${ }^{4}$ Mañé, T. (1891). La enseñanza laica. Las Circunstancias, 05-04-1891. Ver también en: Las Dominicales del Librepensamiento, 12-10-1894.

${ }^{5}$ Mañé, T. (1904). De la Enseñanza Anza. La Revista Blanca, 15-02-1904.
} 
El interés por reformular los métodos de instrucción se extrapoló a todos los frentes que se pudo, entre ellos a las prisiones. Éstas, como consecuencia de la persecución del Estado, se habían transformado en espacios de reclutamiento y campos de cultivo de las ideas librepensadoras. Tal es así que, en los últimos años del siglo XIX, la mayoría de anarquistas habían pasado largas temporadas entre rejas, estableciendo lazos de amistad que durarían toda la vida. Según Juan García Oliver, a "La Modelo" de Barcelona iban a parar representaciones enteras de los sindicatos:

En la Modelo había un continuo entrar y salir de presos sociales. Los talleres 2 y 3 conocieron una animación extraordinaria. Con razón se decía que el paso por la Modelo equivalía a un curso intensivo de estudios superiores de teoría y acción social revolucionarias. La Modelo, para muchos, era una universidad. (García, 1978: 49).

También la prensa ejerció un papel fundamental en la instrucción de los presos, asociándose directamente a ideologías determinadas, especialmente al movimiento obrero (Gargallo 2014: 508). Lily Litvak resaltó la importancia de los periódicos ácratas para la transmisión de las ideas anarquistas, los cuales, además, funcionaron también como herramientas postales (Litvak 2001: 262; Litvak 1989). De hecho, bajo el título Correspondencia, los periódicos -normalmente en la última página- emitían peticiones a personas concretas, sugerencias, críticas a sucesos o a textos, incluso quejas de presos por los maltratos físicos y psíquicos en las cárceles.

Es durante esta etapa cuando en Cataluña los centros de lectura se convirtieron en el eje transformador de la cultura proletaria (Arnabat \& Ferrer 2015). Los obreros, la mayoría analfabetos, acudieron a estos espacios con la finalidad de instruirse y conocer las noticias sociales que les rodeaban. Este tipo de lectura popular y colectiva, que se reprodujo de igual modo en las prisiones, se antepuso a la lectura del libro, forma clásica de acceso individualista a la cultura y, también, medio de cultura burgués (Prado 2011: 36). Si bien Litvak (2001) reconoce muchos otros periódicos, destaca La Revista Blanca, de Madrid; Acracia, Natura y el productor, de Barcelona; El Corsario, de La Coruña; y otros como: Tierra y Libertad, Solidaridad Obrera, Acción Libertaria, La Anarquía, Huelga General o El Porvenir del Obrero.

Es en Reus, ciudad que albergó desde 1859 el "Centre de Lectura" -uno de los primeros ateneos de Cataluña-, donde Teresa Mañé participó en 1894, 
junto a Joan Montseny, en el primer litigio postal por la defensa e instrucción de los presos de este municipio. Reus constituía una de las numerosas ciudades españolas, como Terrassa, Valencia, Alicante, Málaga, Montilla, Jerez, Antequera, etc., donde, según denunciaba el, por entonces, Gobernador Civil de la provincia de Málaga, Antonio Guerola y Peyrolón (1817 - 1901), la prensa que se difundía tenía carácter obrero y era, a su vez, leída por el proletariado: "gracias a este tipo de prensa se fueron popularizando entre las clases populares españolas conceptos como el "asociacionismo", "socialismo", "economía social", etc." (Morales 2002: 42). Años más tarde, Federica Montseny Mañé (1905-1994) definía la capital del Baix Camp de la siguiente manera: "era un centro de irradiación social y política para todo Cataluña" (Montseny 1977: $6)^{6}$.

No debe extrañarnos, por tanto, el conflicto que se generó entre El Diario de Reus y Teresa y Joan por la donación de libros a la cárcel de este municipio. El Diario de Reus remitió a Isidro Díaz - director del centro penitenciario- una nota informándole de las actividades que llevaban a cabo la pareja anarquista "Llamamos la atención al digno Alcaide de las cárceles [...] de algunas de las obras que [...] han regalado con destino á la biblioteca de la cárcel los profesores de la escuela laica de esta ciudad don Juan Monseny y doña Teresa Mañé..."7. La reacción no se hizo esperar. Teresa y Joan decidieron escribir una carta a El Diario de Reus, donde manifestaban su profundo malestar por la noticia:

Retamos á los hombres del Diario á que desde las columnas de esta publicación sostengan con nosotros, desde otras, una polémica, ellos combatiendo las ideas anarquistas por inmorales é ignominiosas y nosotros defendiéndolas por sublimes, justas y perfectas ${ }^{8}$.

Tras la publicación de la carta, El Diario de Reus señalaba -con cierto rencor- que solo había publicado la noticia por cortesía y deferencia:

\footnotetext{
${ }^{6}$ En Reus, en 1893, había un total de 11 escuelas públicas y 30 privadas, de las cuales 4 eran de carácter laico. Archivo Municipal de Reus (AMR), 08-13081174, 27-04-1893. Cabe señalar también que la primera escuela laica de Reus fue inaugurada el año 1870 en el Convento de Sant Francesc. AMR, 08-1402-1181, año $1870-1871$.

7 El Diario de Reus, 23-08-1894

8 El Diario de Reus, 24-08-1894. Esta carta era también recogida por La Autonomía al día siguiente.
} 
Lo que sí debemos hacer presente á los señores firmantes de la carta doña Teresa Mañé y don Juan Montseny que no estamos dispuestos á tolerar ni á ellos ni á nadie que se ponga en tela de juicio nuestra honradez, nuestras costumbres y nuestra vida, que estimamos en tanto como ellos puedan estimar las suyas respectivas. En este terreno no podemos seguirles desde las columnas de nuestro periódico, porque nos lo veda el conocimiento que tenemos de cual deber ser la misión de la prensa [...] Mal que pese á don Juan Monseny y á doña Teresa Mañé el Diario ha sostenido y sostendrá siempre, que la anarquía es una plaga, cuyos frutos son la ignominia y vergüenza del presente siglo; pues no son otra cosa que verdaderos asesinatos: citábamos para corroborarlo el horroroso crimen del Liceo, el atentado de la Gran Vía y la muerte de Carnot, como hubiéramos podido citar otros muchos que hemos tenido que lamentar de algún tiempo á esta parte [...] Eso dijimos, eso hemos dicho multitud de veces: y eso sostendremos, aunque doña Teresa Mañé y don Juan Montseny, se atrevan á calificar de sublimes, justas y perfectas las ideas del anarquismo.

Campo tienen para ensalzarlas cuanto quieran y donde gusten, que por nuestra parte también lo tenemos para combatirlas con todas nuestras fuerzas porque entendemos que á ello nos obligan los horrorosos y repugnantes crímenes de la anarquía ${ }^{9}$.

Ese mismo día, el periódico La Autonomía, que años más tarde mantendría relaciones intermitentes con La Revista Blanca $^{10}$, continuó echando leña al fuego con una serie de acusaciones que se mantendrían durante un tiempo ${ }^{11}$. En una sociedad tan dividida socialmente, evitar que la acracia penetrase en las prisiones y en las escuelas se convirtió en la quimera de la burguesía, celosa de mantener los modelos y patrones sociales.

La semilla del anarquismo ya había germinado en España cuando en 1872 fue declarada ilegal La Federación Regional Española (FRE), solo dos años después de su creación. La Restauración borbónica inauguró un período marcado por una alternancia de gobiernos más preocupados por salvaguardar el

${ }^{9}$ El Diario de Reus, 24-08-1894.

10 La Autonomía, 25-05-1899.

${ }^{11}$ La Autonomía, 24-08-1899; El Diario de Reus, 25-08-1894. La noticia continuaba con otra carta de Teresa Mañé y Joan Montseny hacia El Diario de Reus y sus consiguientes réplicas. La Autonomía 25-08-1891; El Diario de Reus, 26-08-1894; La Autonomía, 26-08-1894. 
orden público que por resolver la miseria de los desheredados del campo y de los trabajadores explotados (Quintero 2016: 41).

La historia del movimiento anarquista de entre siglos está también marcada por el conflicto con las autoridades y la violencia exasperada reprimida por el gobierno. Como reconoce Alicia Berta Quintero (2016) en su reciente tesis doctoral, los hitos más recurrentes en la historiografía son aquellos marcados por la acción, persecución y represión. Entre otros muchos conflictos surgidos a lo largo del periodo, caben destacar: el proceso de La Mano Negra (1882), los sucesos de Jerez (1892), el proceso de Montjuïc (1896) y la Setmana Tràgica, también conocida como la Semana Gloriosa (1909) (Casanova Ruiz 2000).

Gracias al posicionamiento de Teresa Mañé ante estos procesos y, principalmente, ante los presos políticos, Mañé estableció muy buenas relaciones, a lo largo de su vida, con los anarquistas andaluces, como resultado de su implicación en los procesos de La Mano Negra y, más tarde, por su participación en la amnistía que liberó a los encarcelados por la insurrección jerezana (Montseny 1987: 29 y 38-39). De hecho, su estrecha relación con José Sánchez Rosa (1864-1936) la acercó, en diversas ocasiones, hasta Andalucía, donde también manifestó su apoyo a los campesinos encarcelados por las manifestaciones de Lebrija, Carmona, Coruña y Barcelona ${ }^{12}$.

La pareja se convirtió, a finales del siglo XIX, en un referente social y político de la lucha por las ideas y los presos anarquistas. Tras producirse el atentado del 7 de junio de 1896 en la calle Canvis Nous de Barcelona, en el transcurso de la procesión del Corpus, que causó doce muertos y unos cincuenta heridos, las autoridades no vacilaron en recurrir a las detenciones masivas, las torturas y las irregularidades procesales para aplicar un castigo ejemplarizante a cientos de supuestos culpables, entre ellos Joan Montseny (Termes 2011: 153-162). Tras múltiples prácticas tortuosas a los presos, de un proceso judicial lleno de irregularidades y de múltiples condenas, el 4 de mayo de 1897, serían ejecutados en el propio Castillo cinco hombres inocentes (Quintero 2016: 47). Meses antes del fusilamiento, los procesados dirigieron una carta a la embajada francesa en Madrid en la que afirmaban que Tomás Ascheri no era el autor del atentado, cuestión que corroboró el propio acusado en sendas misivas que dirigió a su familia y a la prensa (Avilés 2007: 23).

${ }_{12}$ Mañé, T. Meeting, anarquista en Jérez. La Época, 25-06-1901. 
Joan Montseny sería trasladado desde Reus hasta Barcelona, donde sería recluido, primero en la prisión de hombres de la calle Amalia de Barcelona y después en el castillo de Montjuïc (Montseny 1929-1930: 66-87) ${ }^{13}$. De camino a Barcelona, en la cárcel municipal de Torredembarra, uno de los alguaciles preguntó a Urales:

-¿Quién es usted, que tanto quiere este pueblo? [...]-Un profesor laico de Reus. - ¿De Reus ha dicho? -sí Señor. - ¿Marido de Soledad Gustavo? [...] El guardia se paró y sacó de su mochila un número de "Las Dominicales del Librepensamiento", que contenía un artículo de mí esposa. (Montseny, 1929-1930, vol. I: 88).

Poco después, Teresa, echando mano de sus contactos, enviaba una carta abierta dirigida a Cristóbal Litrán (1861-1926), director de La Autonomía, con el objetivo de presionar a las autoridades y sacar de la cárcel a Montseny y sus otros correligionarios:

Amigo Litrán, V. dirá, seguramente, que por egoísmo le envío mi adhesión á la Asamblea; aunque lo parezca no hay tal; deseo ardientemente salga lo más que se pueda de ella: á la fiera reaccionaria que nos persigue la aplastará la República tan pronto llegue, pues existirá el derecho y la libertad, que son sus verdaderos espantajos.

Se la mando esta abierta, para que puedan enterarse todos los que leen su simpático periódico La Autonomía de mi adhesión á un acto republicano y de la certeza material que tengo de quienes son los perseguidores de la escuela laica. Si no tuvieran pruebas no lo diría; yo no soy como ellos que faltan á los mandamientos de su Dios. Bastante ha costado encontrar el hilo para atrapar el ovillo... ${ }^{14}$

A bordo del crucero Isla Luzón, tras un pacto con las autoridades, se exiliarían hasta Londres algunos de los anarquistas encarcelados en el castillo.

$\overline{13}$ Desde la prisión Joan Montseny escribirá varias cartas a la prensa, con diferentes pseudónimos. En estas reivindicará la inocencia de sus compañeros de lucha.

14 La Autonomía, 11-02-1897. Las relaciones con Joan Montseny cambiaron durante un tiempo como consecuencia de una publicación en La Autonomía, 28-02-1898, en la que Litrán, director de la publicación, criticaba la utilización de pseudónimos para hablar sobre el proceso de Montjuïc. 
Entre los que se encontró la única mujer encarcelada en el proceso: Teresa Claramunt Creus (1862-1931). Poco después, como consecuencia del asesinato de Cánovas del Castillo el 8 de agosto de 1897 (Termes 2011: 161), sería Teresa Mañé quien tendría que exiliarse.

A partir de los procesos de Montjuïc, las campañas pro-detenidos y la deslegitimación de la represión estatal alcanzaron verdadero calado, desbordando, de hecho, las páginas de la prensa obrera, de los periódicos republicanos nacionales e internacionales y llenando los buzones de correspondencia (Quintero 2016: 47).

\section{La Asistencia a Presos de "La Revista Blanca": El Conflicto con la CNT}

Algunas de las fórmulas propias de la solidaridad a presos, tales como las suscripciones y la publicación en prensa de cartas de encarcelados, comenzaban por entonces a cobrar forma (Quintero 2016: 46). La pareja formada por Teresa Mañé y Joan Monteny se mostró, desde muy pronto, participe en este proceso. De hecho, su claro posicionamiento ante los acontecimientos generó, en la segunda etapa de La Revista Blanca (1923-1936), una gran confianza entre los militantes y simpatizantes anarquistas. A partir de entonces, lo que había sido una pequeña editorial pasó a funcionar como una empresa familiar, administrando y gestionando las ayudas y subvenciones económicas a presos políticos y sociales (García Oliver 1978: 216). Mañé había sostenido años antes:

Es preferible, al contrario de lo que el refrán dice, ir mal acompañado que solo, estar en una cárcel en el patio, en medio de criminales, que en una celda de las prisiones celulares; de éstas solo salen estúpidos, de las otras pueden salir individuos beneficiosos ${ }^{15}$.

Una de las propuestas para recaudar beneficios, iniciativa de libertarios de Vigo y Gijón, fue la venta de folletos instructivos, como la obra escrita por Joan Montseny: La Anarquía al alcance de $\operatorname{todos}^{16}$. Otra forma fue a partir

15 Mañé, T. En pos de un ideal. Las dominicales del Librepensamiento, 05-05-1898.

${ }^{16}$ La Revista Blanca, 01-01-1926. 
de la venta de boletos con lo que se intentaron sufragar los gastos de los hijos de los presos anarquistas ${ }^{17}$.

La segunda etapa de La Revista Blanca, a partir de 1923, fue intensa y compleja. Se reeditó a petición de amigos, pero, sobre todo, por la insistencia de Federica Montseny, quien, consciente de la relevancia política que ésta había tenido, quiso devolver a la sociedad esta publicación y sus diferentes suplementos. Mientras tanto, Teresa continuó traduciendo, escribiendo columnas, artículos, administrando la publicación, etc.

Todo ello contribuía, sin duda, a reforzar los lazos de unión y solidaridad entre individuos que, si bien vivían lejos o eran desconocidos, se identificaban entre sí por su sentido de pertenencia a una comunidad ideológica. De hecho, junto con este sentimiento internacionalista se generó también la persecución de los ideales anarquistas a nivel transnacional. En marzo de 1931, el joven Benigno Mancebo Martín (1906-1940), desde el servicio militar en Valencia, donde fue enviado por desertor tras volver de Argentina, respondía a una carta de Teresa. Entre otros asuntos, Mancebo relataba la precaria situación de los anarquistas y sus familiares en Argentina. Éstos eran perseguidos y torturados, independientemente de la edad y condición:

Todo son desgracias para mí en esta hora. Acabo de recibir carta de Buenos Aires, en la cual me comunican que la dictadura de Uriburo ha detenido a mi mamá y la mantiene rigurosamente incomunicada sin dejarla ver por nadie. Y mi hermanito, un muchacho de 14 años, se ha tenido que ir de casa porque también le persigue la policía. Así que ha quedado mi abuelita sola una vieja de 80 años. No dudo que sabréis que a mis dos hermanas, Aurelia e Ysabel después de tenerlas varios días presas en Buenos Aires, fueron desterradas al Uruguay, hallándose actualmente en Montevideo. [...] Claro está que a mí todo eso no me aureola. Yo deseo únicamente que me larguen de esta infame prisión para entregarme, como antes, a la propaganda y defensa de mis ideales. . . 18

$\overline{17}$ Archivo de la Memoria Histórica (AMH). PS Barcelona 831. Carta de Antonio G. Rocamonde a Urales y Federica. Esta carta es enviada desde Chiclana de la Frontera y responde al interés por parte de la asociación sindical de albañiles, peones y similares de remediar las necesidades económicas de los hijos de los reos del Puerto de Santa María.

18 AMH. PS Barcelona 831. Carta de Benigno Mancebo a Teresa Mañé, 16-3-1931. 
Más tarde, Mancebo sería fusilado por el franquismo en la tapia del cementerio de La Almudena de Madrid.

Los lazos de amistad con anarquistas de todas partes también instaron a José Capdevila de Navàs (Lleida), exiliado en Francia en torno al 1934, a escribir a la redacción de La Revista Blanca, solicitando la dirección de anarquistas exiliados para poder albergarse en sus hogares "me dirijo a vosotros para pediros si os es posible comunicación con los compañeros de habla española en Perpiñán o bien con los de Béziers..."19.

A los poderes fácticos les molestaba la presencia y existencia del movimiento obrero, fuese teórico o de acción; sin embargo, la lucha inquebrantable, a pesar de las duras represalias, no haría decaer las esperanzas de la revolución social (Gutiérrez Molina 2008).

La asistencia a los presos no solo acarreó dificultades económicas a la familia. En 1928 Teresa Mañé y Joan Montseny iniciaron un conflicto con el Comité Nacional Pro Presos (CNPP), quien había liderado, hasta entonces, la administración de recursos. Poco tiempo antes de los primeros reproches, Isidro Martínez, miembro del CNPP de la Confederación Nacional de Trabajadores (CNT), escribió a Teresa para confirmar la dirección del Comité; a esta sección sindical, Teresa envió una participación económica a favor de los acusados del proceso de Vallecas ${ }^{20}$. Días después, mediante Teresa, se realizó otro envío de 600 francos por parte de camaradas de Bayona; sin embargo, el dinero nunca llegó a la prisión. Isidro Martínez escribía: “. . . nuestros queridos camaradas que quieren llevarlo asta el fin y tenemos el presentimiento que así sea pues el Director de esta cárcel tiene el corazón de una iena y no se ablandará" 21.

La posición de La Revista Blanca en contra del procedimiento llevado a cabo por el CNPP se dirigió a la CNT, a quien acusaban de defender solo a los miembros de este sindicato. Cabe señalar que éste también albergaba miembros de la Federación Anarquista Ibérica (FAI) ${ }^{22}$. Por contraposición, Juan García Oliver (1902-1980), distanciado tanto de Joan Montseny como de Federica, recordaba que:

${ }^{19}$ AMH. PS Madrid 1615/3, 12. Osséja (Francia). Carta de José Capdevila a La Revista Blanca, 21-10-1934.

20 AMH. PS Barcelona 831. Carta de Isidro Martínez a Teresa Mañé, 3-8-1928.

21 AMH. PS Barcelona 831. Carta de Isidro Martínez a Teresa Mañé, 22-8-1928.

22 AMH. PS Barcelona 831. Carta del CNPP a la redacción de La Revista Blanca, 26-06-1928. 
Poco a poco iban desapareciendo en los penales los elementos más activos del anarcosindicalismo. Era imposible, por falta de medios económicos, hacer frente a los gastos de las defensas ante los tribunales $[\ldots]$

En competencia con el Socorro Rojo Internacional, la familia Urales, cuya Revista Blanca era tolerada por las autoridades, inició en ella una suscripción "pro-presos sociales" que, con el tiempo, llegó a reunir bastante dinero, principalmente de aportaciones de anarquistas y simpatizantes de todo el mundo. En lo tocante al reparto en concepto de ayuda, la Revista Blanca no discriminaba a nadie, bastando dirigirse a ella aportando el nombre y referencia de la organización a que se pertenecía, así como los motivos del encarcelamiento. La contabilidad no era hecha pública.

La organización clandestina local de Barcelona de la CNT interpretó la manera de comportarse de la familia Urales como arbitraria e irresponsable, y pedía que, puesto que la suscripción era pro-presos de la CNT, el comité local y el Comité pro-presos confederal tuvieran conocimiento de lo recaudado por la Revista Blanca y de lo distribuido a presos y perseguidos. A ello se opuso rotundamente la familia Urales, y Federica Montseny tuvo un serio incidente con el compañero Delaville, conocido por "Pere Foix", uno de los miembros de la Comisión local clandestina de la CNT de Barcelona. (García Oliver 1978: 215216).

Las acusaciones del Comité Nacional del Trabajo contra La Revista Blanca generaron disparidad de opiniones. Así se lo harían saber, entre otros, Enrique Blasco y Blanes Rigoberto, quienes bajo el título "El Boicot a la familia" escribían:

A nuestras manos ha llegado un manifiesto firmado por el Comité de la C.N. del Trabajo en el cual, después de decir una serie de sandeces y de un tono poco digno de nuestra estimada y cara Confederación, invitan a todos los anarquistas y sindicalistas a declarar el boicot a La "Revista Blanca". Pues bien [...] pedimos pruebas de las acusaciones que hace contra Urales y su familia [...] Si lo hacemos, es porque La "Revista Blanca" nos es tan querida como la misma Confederación [Y concluía] Para terminar estas líneas solo diremos, que en tantos 
Comités pro presos que ha habido nunca nuestros presos fueron tan bien asistidos como lo son ahora. Y si la "Revista Blanca" cierra su suscripción aconsejamos a todos los compañeros que tomen la actitud de los obreros de Victoria ${ }^{23} \ldots$

También la Federación de Grupos Anarquistas de Lengua Española en Francia se hizo eco. La federación francesa se posicionó en contra de la campaña que había sido, según ella, iniciada por La Revista Blanca:

Desaprobamos vuestra campaña sistemática en estos momentos en que la unidad anarquista se manifiesta fraccionada para entre otras actividades derrocar una situación que nos denigra ante la historia y cuyo estigma pesara sobre nosotros en el futuro si no reaccionamos ${ }^{24}$.

La Revista Blanca, a pesar de las críticas, no cesó en la gestión. En 1932 envió 225 pesetas, a razón de 15 pesetas a cada uno de los reclusos de la cárcel celular de Madrid que, agradecidos, dirigirían una carta firmada en el dorso ${ }^{25}$. Dos años más tarde, la ayuda económica era desorbitada.

El estallido de la Guerra Civil afectó de una manera decisiva al núcleo familiar. Por un lado, Teresa se acabaría separando de Joan Montseny; por otro, la participación de Federica en el gobierno provocaría grandes quebraderos de cabeza a la familia (Lozano 2004).

Teresa Mañé, gravemente enferma de cáncer de colon, abandonó su casa, sus libros, sus recuerdos y su vida. La noche del 25 al 26 de enero de 1939, se inició el exilio. Por el paso fronterizo de Le Pertus, sobre una camilla, fue hospitalizada en una escuela que había sido habilitada. Entonces, el Dr. Santamaría -médico de la División de Buenaventura Durruti- buscó una ambulancia para llevarla a Perpiñán, concretamente hasta el hospital de Saint-Louis. No le dio tiempo a nada más. Murió el 5 de febrero de 1939.

$\overline{23}$ AMH. PS Barcelona 831. Carta de Enrique Blasco y Blanes Rigoberto, Verviers (Bélgica), 03-09-1928. Al apoyo de La Revista Blanca se sumaron diferentes anarquistas como: Faustino García (Tolosa), Vicente Gomís (Alicante).

24 AMH. PS Barcelona 831. Carta de La Federación de Grupos Anarquistas de Lengua Española en Francia a La Revista Blanca, Paris, 24-09-1928. Por entonces esta federación estaba dirigida por Marcel Mochet.

25 AMH. PS Barcelona 831. Carta de los presos de la Cárcel Celular de Madrid a la familia Mañé, Madrid, 22-11-1932. 


\section{Conclusiones}

En definitiva, Teresa Mañé mantuvo relaciones epistolares imprescindibles para comprender la diversidad de anarquismos y sus múltiples funciones y tareas en la sociedad de los siglos XIX y XX. Su labor en La Revista Blanca fue fundamental, no solo corrigiendo y traduciendo textos, sino también como administradora de los recursos destinados a los presos y como publicista y escritora. De hecho, su asidua presencia en los espacios públicos se haría imprescindible en la defensa de los ideales y de los más desvalidos. Volviendo a Kropotkin:

La cárcel no impide que se produzcan actos antisociales. Multiplica su número. No mejora a los que pasan tras sus muros. Por mucho que se reforme, las cárceles seguirán siendo siempre lugares de represión, medios artificiales, como los monasterios, que harán al preso cada vez menos apto para vivir en comunidad. No logran sus fines. Degradan la sociedad. Deben desaparecer. Son supervivencia de barbarie mezclada con filantropía jesuítica. El primer deber del revolucionario será abolir las cárceles: esos monumentos de la hipocresía humana y de la cobardía. No hay porque temer actos antisociales en un mundo de iguales, entre gente libre, con una educación sana y el hábito de la ayuda mutua. La mayoría de estos actos ya no tendrían razón de ser. Los restantes serían sofocados en origen. (Kropotkin 1877).

\section{Agradecimientos}

Este trabajo es uno de los resultados del GRAMP-UB (Generalitat de Catalunya 2017 SGR 833).

\section{Bibliografía}

1. Arenal, C. (1865). Carta a los delincuentes. Coruña: Imp. del Hospicio.

2. Arnabat Mata, R. \& Ferrer Trill, X. (2015). Ateneus. Cultura i llibertat. Associacionisme a la Catalunya contemporània. Barcelona: Federació d'Ateneus de Catalunya. 
3. Avilés, J. (2007). La lógica del terrorismo: El caso de los atentados anarquistas en España, 1892-1897. In Seminario de Historia Contemporánea Instituto Universitario de Investigación Ortega y Gasset.

4. Beaumont, G. de \& Tocqueville, A. de (1833). On the penitentiary system in the United States.

5. Biglia, B. (2012). Corporeizando la epistemología feminista: investigación activista feminista. In Liévano Franco, M. \& Duque Mora, M. (Comp.), Subjetivación femenina: investigación, estrategias y dispositivos críticos (pp. 195-229). Nuevo León: Universidad Autónoma de Nuevo León.

6. Casanova Ruiz, J. (2000). La cara oscura del anarquismo. In Julià Díaz, S. (dir.), Violencia política en la España del siglo XX (pp. 67-104). Madrid: Taurus.

7. England, K. (1994). Getting personal: Reflexivity, positionalit y and feminist research. The Professional Geographer, 46: 80-89.

8. Foucault, M. (2000). Vigilar y castigar, nacimiento de la prisión. Madrid: Siglo XXI.

9. Gargallo Vaamonde, L. (2014). Desarrollo y destrucción del sistema liberal de prisiones en España: De la Restauración a la Guerra Civil. Tesis doctoral, Universidad de Castilla-La Mancha.

10. García Oliver, J. (1978). El eco de los pasos. Barcelona: Ibérica de Ediciones y publicaciones.

11. Girón, Á. (2002). Los anarquistas españoles y la criminología de Cesare Lombroso (1890-1914). Frenia, 2: 81-108.

12. Gutiérrez Molina, J. L. (2008). El Estado frente a la anarquía. Los grandes procesos contra el anarquismo español (1883-1982). Madrid: Síntesis.

13. Kropotkin, P. A. (1877). Las cárceles y su influencia moral sobre los presos. Paris.

14. Iturbe, L. (1994). La mujer en la lucha social y en la guerra civil de España. México D. F.: Editores Mexicanos Unidos.

15. Litvak, L. (1989). El delincuente y la justicia en la obra literaria del anarquismo español 1880-1913. Archipielago: Cuadernos de crítica de la cultura, 3: 52-61

16. Litvak, L. (2001). Musa Libertaria. Madrid: Fundación de estudios Anselmo Lorenzo.

17. Lombroso, C. (1876). El hombre delincuente.

18. Lozano Domingo, I. (2004). Federica Montseny: Un anarquista en el poder. Madrid: Espasa Calpe.

19. Marín Silvestre, D. \& Palomar y Abadia, S. (2010). Els Montseny Mañé. Un laboratori de les idees. Reus: Carrutxa.

20. Micó Millàn, J. (2001). Teresa Mañe y Miravet en Retrat 16. Vilanova i la Geltrú: editado por el Ayuntamiento de Vilanova i la Geltrú.

21. Méijome Tejero, A. (2013). Anarcofeminismo e identidad(es): una mirada histórica al anarcofeminismo en el Estado Español. Revista Internacional de Pensamiento Político, 8: 81-94. 
22. Montesquieu (1762). El espíritu de las leyes.

23. Montseny, F. (1977.) Cent diez de la vida d'una dona (1939-1940). Barcelona: Galba edicions.

24. Montseny, F. (1987). Mis primeros cuarenta años. Barcelona: Plaza \& Janes editors.

25. Montseny, J. (1929-1930). Mi Vida. Barcelona: La Revista Blanca, 3 vol.

26. Morales Muñoz, M. (2002). Cultura e ideología en el anarquismo español (-1910). Málaga: Monografías núm. 17, centro de Ediciones Diputación Provincial de Málaga.

27. Prado, A. (2011). Matrimonio, familia y Estado: escritoras anarco-feministas en La Revista Blanca (1898-1936). Madrid: Fundación de Estudios Libertarios Anselmo Lorenzo.

28. Quintero Maqua, A. B. (2016). El eco de los presos. Los libertarios en las cárceles franquistas y la solidaridad desde fuera de la prisión, 1936-1963. Tesis doctoral, Universidad Complutense de Madrid, Madrid.

29. Termes, J. (2011). Història del moviment anarquista a Espanya (1870-1980), Barcelona: L'Avenç.

\section{Author's Biodata}

Ginés Puente Pérez (Vila-seca, 1991) finalizó los estudios de Historia en 2013 y el Máster en Estudios de Mujeres, Género y Ciudadanía en 2016. Ha trabajado durante 5 años en la Universitat Rovira i Virgili (Tarragona) como becario de proyecto y asistente docente de máster en el grado de Historia; también ha desarrollado un estudio toponímico en La Selva del Camp (Tarragona), a partir de una beca local, y dos proyectos de descripción documental en la Biblioteca de Cataluña. Ha publicado varios trabajos, todos ellos enmarcados en el siglo XIX. Entre otras temáticas ha estudiado los procesos migratorios hacia América Latina (XVIII-XIX), la construcción de las nuevas redes de comunicación catalanas (XIX), los procesos de secularización (XIX$\mathrm{XX}$ ) y, en la actualidad, su línea de investigación doctoral es la formación de las identidades anarco-feministas. Más concretamente, el estudio de la obra y la vida de Teresa Mañé Miravent, conocida también con el pseudónimo de Soledad Gustavo. 